cussion of the optical properties and problems of multifocal lenses.

The text is in very large print, N12 equivalent, (so that the beginner can refer to it in the dim light of the consulting room?). In contrast, many of the diagrams tend to be relatively small with crowded lines.

In short, a layman could plausibly conduct a simple sight test after reading this book but without sound understanding of the subject. Mercifully, sight testing is still the province of the qualified ophthalmologist and optometrist according to the law of this country. The information contained in this book would not begin to satisfy the requirements of the professional examining boards in the UK and I cannot recommend it to our junior staff.

H. J. Frank

\section{Ophthalmic Clinical Debates}

Thomas A. Deutsch

This book is written as a series of small debates and contains an eclectic mixture of subjects, all of which are common topical problems encountered in clinical practise.

The format of each chapter consists of a theoretical 'short case' introduced to highlight a specific therapeutic problem. Two contributors are then invited to discuss their approach to the management of this case.

The introduction admits that the 'debates' were often manufactured. In some sections the pairs of authors put forward arguments so similar that they concur. Other cases reveal only two plans of management when there are plainly many more to choose from. However, the book aims to broaden the readers outlook on the manifold possibilities of investigation and treatment of certain problems in which there is no certain right or wrong path to follow. This it achieves well.

Ophthalmic Clinical Debates has a very American approach to its problem solving not only in its entertaining phraseology but also in the organisation of the practitioners 'office' and routes of referral which often differs from the arrangement in this country.

The editor states that the book is a 'potpourri of common ocular problems' and I feel that it is a good coffee table book to dip into. It provides an adjunct to standard textbooks and is of value to ophthalmologists at all levels in refreshing and updating their management regimes.

Ruth Manners

\section{Contact Lenses in Ophthalmology}

M. S. Wilson, E. A. W. Millis

Butterworth \& Co Ltd 1988

This is a concise and readable book which achieves its aims as an introductory text both for the ophthalmologist who wants to know more about the applications of contact lenses as well as those wishing to start lens fitting. The introductory chapters, with frequent use of summary tables, will be useful reading for those new to the field. The almost complete omission of the optics of lenses may be regarded with relief by some although an expansion here might further clarify the indications for different lens types. The subsequent chapters on the equipping of a practice and the choice and fitting of different lenses are good but with an unfashionable emphasis on the use of PMMA. The complications of lens wear are dealt with separately for each lens type which leads to some duplication and loss of consistency where more guidance in the diagnosis and management would be helpful. The final chapters deal concisely with the medical applications of lens use. There are useful references at the end of each chapter and a bibliography to guide the reader to alternative sources. Despite these reservations it is one of the best introductory texts on contact lenses for the ophthalmologist.

John Dart

\section{Greer's Ocular Pathology}

4th edition ed D. Lucas

Blackwell Scientific Publications

Greer, used by generations of aspiring ophthalmologists in Australia and the UK, has undergone a face-lift. In preparation for ten years, the new edition has changed size, shape and format. The transformation is more than skin-deep though and Dr David Lucas has improved the range of topics covered, the volume is profusely and well illustrated and a greater number of recent and comprehensive 